\title{
Within-Population Isotopic Niche Variability in Savanna Mammals: Disparity between Carnivores and Herbivores
}

\author{
Daryl Codron ${ }^{1,2 *}$, Jacqueline Codron ${ }^{3}$, Matt Sponheimer ${ }^{4}$ and Marcus Clauss ${ }^{5}$ \\ ${ }^{1}$ Florisbad Quaternary Research Department, National Museum, Bloemfontein, South Africa, ${ }^{2}$ Centre for Environmental \\ Management, University of the Free State, Bloemfontein, South Africa, ${ }^{3}$ Karoo Palaeontology Department, National Museum, \\ Bloemfontein, South Africa, ${ }^{4}$ Department of Anthropology, University of Colorado at Boulder, Boulder CO, USA, ${ }^{5}$ Clinic for \\ Zoo Animals, Exotic Pets and Wildlife, Vetsuisse Faculty, University of Zurich, Zurich, Switzerland
}

OPEN ACCESS

Edited by:

Jason Newton,

Scottish Universities Environmental

Research Centre, UK

Reviewed by:

Cang Hui,

Stellenbosch University, South Africa Sergio Andrés Estay,

Universidad Austral de Chile, Chile Grant C. Hopcraft,

University of Glasgow, UK

*Correspondence:

Daryl Codron

d.codron@nasmus.co.za

Specialty section:

This article was submitted to

Population Dynamics,

a section of the journal

Frontiers in Ecology and Evolution

Received: 26 September 2015

Accepted: 09 February 2016

Published: 29 February 2016

Citation:

Codron D, Codron J, Sponheimer M and Clauss M (2016)

Within-Population Isotopic Niche Variability in Savanna Mammals:

Disparity between Carnivores and Herbivores. Front. Ecol. Evol. 4:15.

doi: 10.3389/fevo.2016.00015
Large mammal ecosystems have relatively simple food webs, usually comprising three-and sometimes only two-trophic links. Since many syntopic species from the same trophic level therefore share resources, dietary niche partitioning features prominently within these systems. In African and other subtropical savannas, stable carbon isotopes readily distinguish between herbivore species for which foliage and other parts of dicot plants $\left({ }^{13} \mathrm{C}\right.$-depleted $\mathrm{C}_{3}$ vegetation) are the primary resource (browsers) and those for which grasses $\left({ }^{13} \mathrm{C}\right.$-enriched $\mathrm{C}_{4}$ vegetation) are staples (grazers). Similarly, carbon isotopes distinguish between carnivore diets that may be richer in either browser, grazer, or intermediate-feeding prey. Here, we investigate levels of carbon and nitrogen isotopic niche variation and niche partitioning within populations (or species) of carnivores and herbivores from South African savannas. We emphasize predictable differences in within-population trends across trophic levels: we expect that herbivore populations, which require more foraging effort due to higher intake requirements, are far less likely to display within-population resource partitioning than carnivore populations. Our results reveal generally narrower isotopic niche breadths in herbivore than carnivore populations, but more importantly we find lower levels of isotopic differentiation across individuals within herbivore species. While these results offer some support for our general hypothesis, the current paucity of isotopic data for African carnivores limits our ability to test the complete set of predictions arising from our hypothesis. Nevertheless, given the different ecological and ecophysiological constraints to foraging behavior within each trophic level, comparisons across carnivores, and herbivores, which are possible within such simplified foodwebs, make these systems ideal for developing a process-based understanding of conditions underlying the evolution of intra-specific, individual-level separation of ecological niches.

Keywords: Africa, carbon isotopes, feces, individual specialization, niche overlap, nitrogen isotopes 


\section{INTRODUCTION}

Assemblages of large-bodied mammals exist in relatively simple foodwebs, in which the various food chains typically have only three (plant, herbivore, carnivore), and sometimes-as in the case of elephants that largely escape predation-only two links. Herbivores in these systems exist in one of three feeding guilds, either as browsers (consumers of trees and shrubs), grazers (grass feeders), or intermediate-feeders (Hofmann, 1973, 1989; Gagnon and Chew, 2000; Clauss et al., 2008). In African savannas and other subtropical environments, stable carbon isotopes track herbivore feeding styles, because of the well-known bimodal distribution of carbon isotope compositions amongst $\mathrm{C}_{3}$ (mainly browse) and $\mathrm{C}_{4}$ (grass) vegetation (Vogel, 1978; Vogel et al., 1978; Tieszen et al., 1979; Cerling and Harris, 1999). Thus carbon isotopes have been successfully used to test hypotheses about browsing and grazing in African savannas across taxa, across populations through space and time, and through fossil lineages over evolutionary time (Tieszen et al., 1989; Koch et al., 1995; Cerling et al., 2003, 2015; Sponheimer et al., 2003a; Botha and Stock, 2005; Codron et al., 2006, 2008a, 2011b, 2012b; Djagoun et al., 2013; Lehmann et al., 2013; Radloff et al., 2013). Large mammal carnivores have more complex diets, the composition of which is determined largely by predator-prey body size relationships (Carbone et al., 1999, 2007; Gervasi et al., 2015). Nonetheless, carnivore carbon isotope compositions should, in principle, reflect prey availability within their habitats; they may, for instance, show higher levels of $\mathrm{C}_{4}$ biomass intake in more open habitats (Codron et al., 2007a; Ben-David and Flaherty, 2012). In both herbivores and carnivores, however, the focus of most isotopic research has been on variations between species and between their populations, while less attention has been given to the variation within populations. Here we develop a concept of how patterns of intrapopulation dietary variations may differ for large mammal herbivore species compared with carnivore species, and we discuss how existing and future stable isotope approaches can be used to test its predictions.

The theoretical framework for understanding dietary variation within populations was provided by Van Valen (1965), who discussed two scenarios: a population's niche breadth can expand either because each individual's niche breadth expands, or because each individual occupies a relatively narrow range of the total dietary niche space and the addition of individuals to the population leads to a wider overall niche breadth. Subsequent reviews have found evidence that dietary specialization within individuals is a somewhat prevalent phenomenon across a wide range of taxa, including invertebrates, fish, herpetiles, and mammals (Bolnick et al., 2003, 2007; Araújo et al., 2011). Such phenotypic variation within populations emerges as an important mechanism whereby animals mitigate the effects of competition for resources in limiting environments, and is an important driver of evolution by natural selection, in particular disruptive selection (Pfennig et al., 2010; Bolnick et al., 2011; Robertson et al., 2015). In this context, a powerful application of stable isotope approaches is that serial analysis along the growth axis of incremental tissues, such as hair, teeth, and scales resolves longitudinal records of the diets of individuals (Araújo et al., 2007, 2011). Using this approach, within-individual diet specializations have been confirmed for species such as turtles, eels, seals, sea otters, badgers, martens, and others (Ben-David et al., 1997; Cherel et al., 2009; Newsome et al., 2010; Vander Zanden et al., 2010, 2013; Cucherousset et al., 2011; Robertson et al., 2014). However, multi-decadal isotopic records extracted for African elephants (Loxodonta africana), the largest mammalian herbivore, revealed within-individual isotopic variations that were as pronounced as that of the whole population over the measured time period (Codron et al., 2012b).

Clearly, although a widespread phenomenon, individualization of dietary niches is not necessarily universal. The case for elephants hints at constraints related to herbivory that may restrict the prevalence of diet specialization within individual large-bodied herbivores. The most obvious reason for this is that because herbivores feed on low-quality food, they have substantially higher absolute intake requirements compared to carnivores (Bourliére, 1975; Van Soest, 1994). They therefore need to feed much more regularly and cannot afford to waste time searching for specific food items in a heterogeneous environment, especially if resources are limiting. Because this effect operates at the level of the individual, inter-individual niche variation should be a less suitable strategy for large-bodied herbivores than it is for carnivores.

The aim of this paper is to determine how stable isotope analyses can be used to test the hypothesis that large-bodied mammalian carnivore and herbivore species have disparate patterns of intrapopulation dietary variation, i.e., that this phenomenon may be prevalent within carnivore populations, but far less so within herbivore populations. We develop a simple model to simulate intrapopulation niche variation based on differences in absolute intake requirements, and use stable isotope data from free-ranging populations to test predictions of the model. We explore novel analytical approaches of existing isotope datasets derived from mammal feces, although this necessarily restricts the study to investigations of short-term dietary niche partitioning rather than persistence of patterns within individuals. We provide preliminary data for longerterm dietary patterns in savanna herbivores from tooth and hair isotope profiles, and discuss the information still needed to test and ultimately refine the overall hypothesis.

\section{MATERIALS AND METHODS}

\section{Simulation Experiment}

The hypothesis underpinning this study is that herbivores, due to higher intake requirements, are less likely to develop specialized dietary strategies at individual level than are carnivores. As an initial exploration, we undertook a brief, simple simulation exercise to explore some of the ramifications of this hypothesis. For an individual predator foraging on $i$ number of available food items, biomass intake $(I)$ is easily calculated as

$$
I=\sum n_{i} M_{i}
$$

where $n$ is the number of individuals taken, and $M$ the prey mass. Various factors influence $n_{i}$, the most important of which is the 
relative abundance of prey type $i$ in the foraging matrix $\left(E_{i}\right)$ as this regulates encounter rates with prey (Stephens and Krebs, 1986). However, $n_{i}$ will also be influenced by the probability of a successful attack $\left(s_{i}\right)$, and ultimately by the absolute number of attacks or foraging bouts made $(A)$, so that

$$
n_{i}=A E_{i} s_{i} x_{i}
$$

The parameter $x_{i}$ in Equation (2) represents a selection factor $\left(x_{i}\right)$ that allows comparison between individual generalist with individual specialist foraging strategies: for a generalist strategy, $x=1$ for all $i$ as the individual predator has an equal probability of attacking any encountered prey type, but for a specialist strategy $x=1$ only when $i=j$ (where $j$ is the preferred prey type) and is 0 for all other $i$ (note that in our simulations we used $x_{i}=0.1$ for non-preferred prey items to allow for opportunistic foraging).

An additional factor we consider is that whereas carnivores are true predators that typically kill and consume whole prey individuals, herbivores consume only a portion of each individual plant they feed on (e.g., Begon et al., 2006). Factoring the average fraction of each individual prey item consumed from each prey type ( $f$ ), and Equation (2), into Equation (1) gives

$$
I=A \sum E_{i} s_{i} x_{i} M_{i} f_{i}
$$

From the above, we can calculate the average degree of niche overlap between individuals within a population of $k$ number of predators, by estimating relative contributions of each prey type to the diets of individuals $\left(p_{i}\right)$ from Equation (2), and from the resultant electivity matrices calculating niche overlap between individual pairs ( $k$ and $l$ ) using Pianka's (1986) index

$$
O_{k l}=\frac{\sum p_{i k} p_{i l}}{\sqrt{\sum p_{i k}^{2} \sum p_{i l}^{2}}}
$$

For $O_{k l}=0$, individuals $k$ and $l$ have distinct niches, but have identical (overlapping) niches for $O_{k l}=1$. Our hypothesis would be supported if niche overlap is generally higher within herbivore populations than within carnivore populations, indicating broader niche breadths and hence more generalist diets at individual level in the former. Further support for our hypothesis could be inferred if average foraging effort ( $A$; solved using Equation 3 ) across all individuals within a population is significantly higher for herbivores than carnivores, especially for herbivores with individualized foraging strategies.

We simulated outcomes of foraging under these conditions across individual generalists and individual specialists amongst carnivore and herbivore populations of 50 individuals $(k)$ each, and each population having five food types available ( $i)$. Further, we explored outcomes for predators of different sizes (i.e., 10, 100 , and $1000 \mathrm{~kg}$ ). Prey sizes (in $\mathrm{kg}$ ) were set at $1 / 5,2 / 5, \ldots$ of predator body size, since predators typically feed on prey equal in size or smaller than themselves (e.g., Brose et al., 2006). Initial prey abundances, and $E_{i}$, were based on allometric estimates assuming a size-abundance scaling of -0.75 (Damuth, 1987), and were decreased by $\sum n_{i k}$ sequentially so that outcomes would also capture density-dependent effects on resource availability. Differences between carnivores and herbivores are based mainly on differences in intake requirements $(I)$ across trophic levels, which we estimated based on body size-dry matter intake (DMI) allometries. Intake requirements of both herbivores and carnivores scale to approximately 0.75 of body mass $(0.761 \pm$ $0.032,95 \% \mathrm{CI}$ and $0.702 \pm 0.080$, respectively), but the allometric intercept for the former is significantly higher $(0.047 \pm 0.006$ and $0.033 \pm 0.008$, respectively; data from Clauss et al., 2007; and Clauss, unpublished data compilation from carnivore digestion studies). Finally, $s_{i}$ for each predator individual was a random number between 0 and 1 (since we make no $a$ priori assumptions about differences in foraging success) and $x_{i}$ and $f_{i}$ differed between foraging strategies as described above. We present results of average niche overlap $(O)$ and foraging effort $(A)$ as means and 95\% confidence intervals from 1000 iterations of these models. Simulations were carried out using the Visual Basic for Applications (VBA) editor of Microsoft Excel 365.

\section{Fecal Isotope Dataset}

Fecal isotope data used for this study were obtained by mining previously-published datasets for assemblages comprising both carnivorous and herbivorous large-bodied mammal species (Codron et al., 2005a, 2007a,b). These data are derived from fecal samples collected in the field from the Kruger National Park (KNP; between $22^{\circ} 20^{\prime}$ to $25^{\circ} 32^{\prime} \mathrm{S}$ and $30^{\circ} 32^{\prime}$ to $32^{\circ} 02^{\prime}$ E) and Welgevonden Private Game Reserve (WPGR; $24^{\circ} 14^{\prime} \mathrm{S}$, 27o15' E), South Africa, both reserves representing "typical" southern African savanna environments. Datasets for other African savanna regions both our own and from other literature sources-do not have sufficient samples of both carnivores and herbivores to address our questions.

We subdivided the dataset into three distinct habitats: KNP North, KNP South, and WPGR. Details of these study areas are described elsewhere, but for our purposes here it is sufficient to note that WPGR is a distinct reserve in the Waterberg region of South Africa, a mountainous savanna area in the Northwest of the country, whereas KNP lies in the low-lying savannas of the Northeast. While KNP comprises a diversity of habitat types (Venter et al., 2003), we merely distinguish between the northern and southern regions of the Park based on a distinct difference in vegetation between the two-the former having an homogeneous woody plant component, while the latter is a more heterogenous woodland savanna. These regions are also separated by a natural ecological barrier, the centrally-located Olifants River.

We confined the data recovered to include only specimens collected during dry season months (April to September) between 2002 and 2005, because wet season specimen numbers for carnivores are very small. Nonetheless, especially amongst herbivores, resource limitation during dry seasons is more likely to reveal noticeable levels of isotopic and dietary variation than would be expected for the rainy season (Illius and Gordon, 1987). We further confined the data to include only those species for which sample size was $\geq 6$ as a minimum requirement for non-parametric descriptives of variability (Zar, 2010). Represented carnivores include three species: spotted 
hyaena (Crocuta crocuta), lion (Panthera leo), and brown hyaena (Hyanea brunnea), of which only the spotted hyaena is represented by more than one population, i.e., KNP North and KNP South. We excluded herbivore species that generally do not form parts of these foodwebs, i.e., the megaherbivores (elephants, hippopotamus Hippopotamus amphibius, and rhinoceroses Ceratotherium simum and Diceros bicornis), and very small herbivores including common duiker (Sylvicapra grimmia), and steenbok (Raphicerus campestris) since such small animals do not form a major component of the diets of the largest mammalian carnivores in these systems (Carbone et al., 1999; Radloff and Du Toit, 2004; Hayward and Kerley, 2005). In all, the dataset is heavily biased toward herbivores (1192 specimens distributed across 12 species, whereas the three carnivore species included here are represented by only 36 specimens; Table 1), reflecting the general paucity of isotopic studies that have been carried out on African mammalian carnivores.

\section{Data Analysis}

Our first objective in analysing the fecal dataset was to determine patterns of prey selection in each population of carnivores and herbivores. Thus, each fecal specimen was assigned to a $\mathrm{C}_{3^{-}}, \mathrm{C}_{4^{-}}$, or mixed- prey base determined by its $\delta^{13} \mathrm{C}$ value. For herbivores, dietary designations were based on comparisons with $\delta^{13} \mathrm{C}$ values of local vegetation (Codron et al., 2013b). Assuming a diet-feces discrimination effect of $-0.8 \%$, a constant derived for both $\mathrm{C}_{3}$ - and $\mathrm{C}_{4}$-based diets from controlled-feeding experiments with mammalian herbivores (Codron et al., 2005b, 2011a), each herbivore specimen was taken to reflect either a $\mathrm{C}_{3}$-based diet (if discrimination-adjusted $\delta^{13} \mathrm{C}$ values fell within the range of values of local $\mathrm{C}_{3}$ vegetation), a $\mathrm{C}_{4}$-based diet (if $\delta^{13} \mathrm{C}$ values were within the range of $\mathrm{C}_{4}$ grasses), or a mixed diet (intermediate $\delta^{13} \mathrm{C}$ values). Qualifying carnivore diets is more complicated because they consume a variety of prey body tissues which vary greatly in isotopic composition (Tieszen et al., 1983; Lee-Thorp et al., 1989; Passey et al., 2005; Codron et al., 2012a). For the present study, we assumed that the bulk of ingested material is prey muscle tissue, which in large herbivores is $\sim 2.3 \%$ o higher in $\delta^{13} \mathrm{C}$ than feces (Sponheimer et al., 2006). Assuming a similar diet-feces discrimination effect as for herbivores, carnivore feces were then assigned to prey groups of either $\mathrm{C}_{3}$-feeders (if adjusted $\delta^{13} \mathrm{C}$ values fell within the range of values for available browser feces), $\mathrm{C}_{4}$-feeders (if $\delta^{13} \mathrm{C}$ values fell within the range of values for grazer feces), or intermediate-feeders (if $\delta^{13} \mathrm{C}$ values fell between the browser and grazer ranges). This conservative approach simplifies the level of diet resolution to a relatively crude scale which we believe is necessary given limitations within our dataset. Nevertheless, a simple distinction between $\mathrm{C}_{3}{ }^{-}, \mathrm{C}_{4^{-}}$, or mixed-feeding has been considered sufficient for many approaches to foodwebs in large-bodied savanna mammals (e.g., Owen-Smith, 1997; Du Toit, 2003), and allows for a rapid comparison of dietary differences between individuals and, for the present study, of patterns across trophic levels.

The next step in our analysis was to resolve differences in levels of isotopic variability within populations between carnivores and herbivores. Because sample sizes representing carnivore populations were small, we used a non-parametric descriptive, the interquartile range (IQR), to define the range of isotopic variability within each population. For this analysis, we also included fecal stable nitrogen isotope data, as these values are known to record differences in trophic level (Minagawa and Wada, 1984), as well as-potentially-environmental, ecophysiological, and nutritional stress levels experienced by mammalian herbivores (Ambrose, 1991; Sponheimer et al., 2003c; Robbins et al., 2005). Simultaneous analysis of more than one isotope generally resolves greater levels of dietary niche complexity in consumers than a single isotope on its own (Phillips et al., 2005). Here, we measured the isotopic niche breadths of each population as the standard area of ellipses, adjusted for small sample sizes (SEAc), in stable $\mathrm{C}$ and $\mathrm{N}$ isotope bi-space (Jackson et al., 2011). Finally, in order to estimate the level of variability across individuals, we used the average of all Euclidean distances (ED) between individual pairs. This approach differs from previous efforts using longitudinal data for individuals (e.g., Newsome et al., 2009; Vander Zanden et al., 2010; Codron et al., 2012b, 2013a; Robertson et al., 2014). We demonstrate here how insights into individual-level differences can be drawn in the absence of such temporal series, and discuss the advantages and drawbacks below.

Given that carnivores are represented by comparably fewer samples relative to herbivores in our data, there is a great deal of uncertainty for comparing metrics between the two trophic groups. To compare the IQR, SEAc, and ED of carnivores with herbivores, we used permutations tests based on randomized subsamples of data. The size of sample subsets ranged from one to the number of carnivores represented within each assemblage. Using this approach, we (a) determine whether our sample sufficiently captures the extent of isotopic variability within populations (i.e., if metrics asymptote when plotted over increasing sample size), and (b) compare metrics for similar sample sizes for each population included. Herbivores were considered to have narrower isotopic niche breadths than carnivores if IQRs, SEAc, and ED of the former were smaller in $>95 \%$ of $10^{4}$ iterations. These analyses were carried out using $\mathrm{R}$ 2.14.0, using the SIBER package contained within the SIAR library to compute SEAc (Jackson et al., 2011).

\section{Tooth and Hair Isotopic Profiles}

One of the limitations to this study is that fecal data are shortterm and therefore do not show whether patterns are persistent through time (see Discussion, and above). We provide a cursorial analysis of a small sample of carbon isotope time series data, derived from tail hair and tooth dentine collagen profiles of herbivores from similar southern African savannas, to further test the hypothesis that individual level niche separation is scarce in this group. Teeth of three individual grazers, and three individual intermediate-feeders, as well as tail hairs from four individual grazers, were sampled incrementally along their growth axes. Teeth from the collections of the Florisbad Quaternary Research Station, National Museum, Bloemfontein, were sampled by drilling dentine powder using a diamond-tipped microdrill with a $1 \mathrm{~mm}$ burr at 5-20 $\mathrm{mm}$ increments from the dentino-enamel junction to the root tip. Dentine powder was prepared using standard collagen isolation methods (e.g., Codron et al., 2008c). 


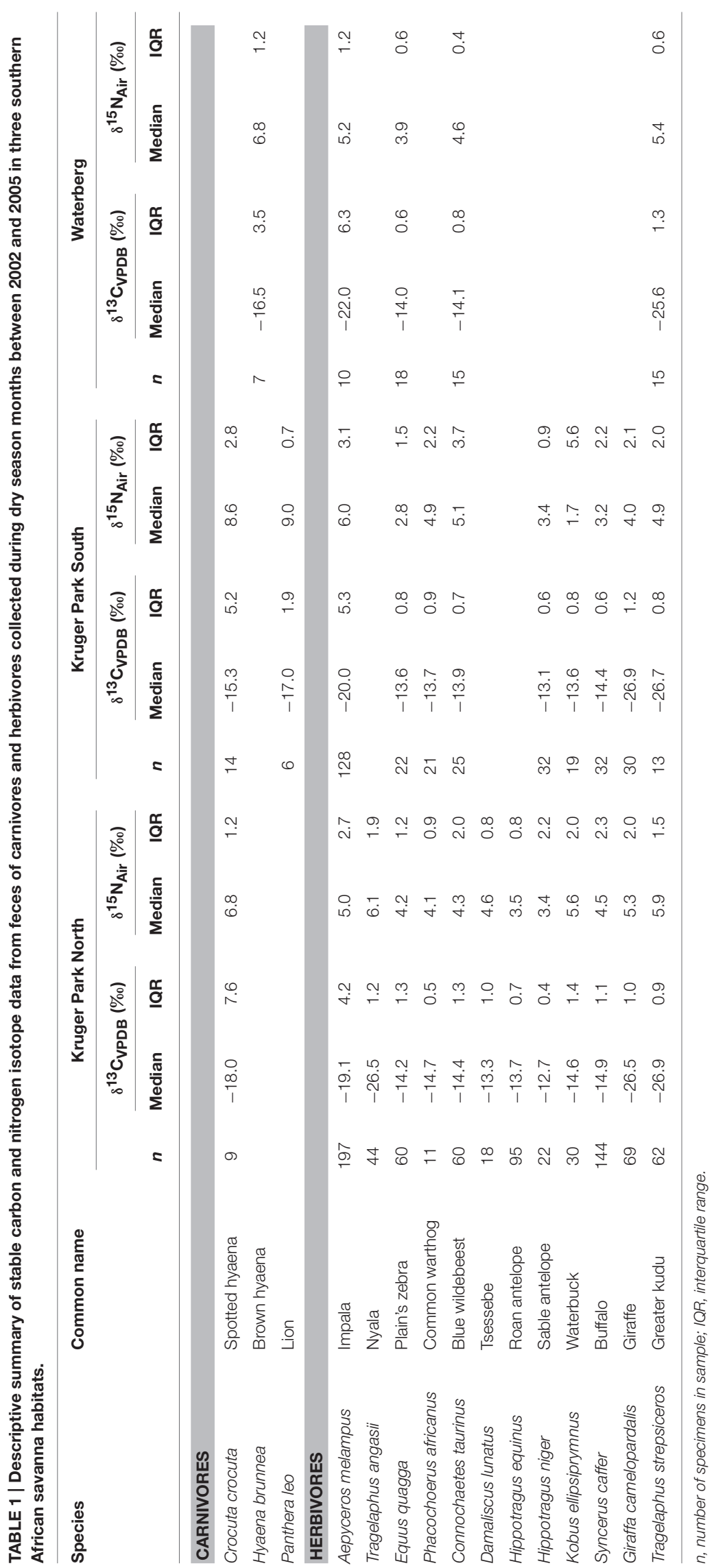


Tail hairs, collected by rangers from free-ranging animals in the KwaZulu-Natal midlands in the eastern parts of South Africa, were cleaned with acetone and then serially sectioned in increments of $2 \mathrm{~mm}$ for teeth, and between 10 and $20 \mathrm{~mm}$ for hair, working from root to tip. Individual microsamples were analyzed for stable carbon isotope compositions using standard methods described elsewhere (see e.g., Codron et al., 2008c).

Stable carbon isotope values from tooth dentine are presented as hair equivalents, assuming a difference in diet-hair and dietcollagen ${ }^{13} \mathrm{C}$ fractionation effects of $+2.4 \%$ (Tieszen et al., 1983; Lee-Thorp et al., 1989; Ambrose and Norr, 1993; Sponheimer et al., 2003b; Cerling et al., 2006). Carbon isotope series of individuals were then compared using one-way ANOVAs, with Individual as a random effect, and Bonferonni post-hoc tests for multiple comparisons where necessary. Variance components analyses (VCAs) were used to quantify within-vs. betweenindividual sources of variance in the data (e.g., Newsome et al., 2009; Vander Zanden et al., 2010). Similar analyses were used to test for individual-level variations amongst serially-sampled hairs of nine chacma baboons (Papio hamadryas ursinus) collected from the WPGR in September 2002 (data from Codron et al., 2008c). Although not ungulates, baboons are largely herbivorous (e.g., Whiten et al., 1991), and hence should be subject to at least some of the same constraints faced by ungulate herbivores. ANOVAs and VCAs were carried out in STATISTICA v12.0 (Dell Inc, 2015).

\section{RESULTS}

\section{Model Simulations}

Simulations revealed that average niche overlap amongst individuals within six types of populations (individual generalist and individual specialist carnivores and herbivores, respectively, as well as generalist and specialist herbivores consuming only small portions of each prey item, i.e., $f_{i}<1$ ) was generally higher for herbivores than for carnivores, although no differences between trophic levels were found for small-bodied predators (Figure 1A). Lower levels of niche overlap were expected within populations of individual specialists compared with populations of individuals with generalist niches; our simulations only revealed such effects amongst carnivores, but not amongst herbivores. Foraging effort (i.e., the average number of foraging bouts per individual) was necessarily higher for herbivores than carnivores, given the higher intake requirements of the former, with the difference becoming even more pronounced amongst populations of individual specialists (Figure 1B). The higher foraging effort required by herbivores was even more pronounced in cases where $f_{i}<1$. Larger-bodied predators required less foraging effort to achieve intake requirements, which is not surprising given the larger-sized prey available to them, and the lower intake requirements (relative to body mass) of larger animals with relatively lower metabolic rates.

\section{Fecal Isotope Dataset}

Despite the smaller sample size for carnivores than herbivores, fecal isotopic variability amongst individual carnivores was similar to or even greater than that recorded for herbivores

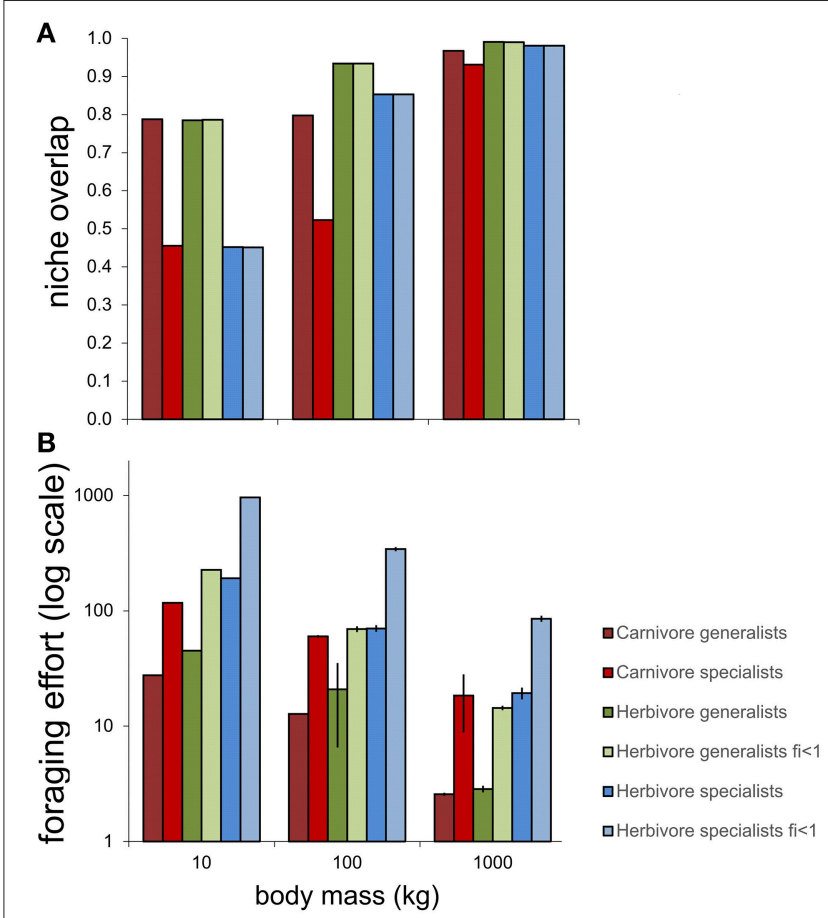

FIGURE 1 | Simulated patterns of (A) average niche overlap between individuals and $(B)$ average foraging effort of individuals, within populations of mammal carnivores, and herbivores of different body sizes. Niche overlap is calculated using Pianka's (1986) index; foraging effort is estimated as the number of foraging bouts required for individuals to achieve intake requirements. Generalists are defined as populations in which individuals consume any prey item they encounter, specialists as populations in which individuals consume prey of only one type. The parameter $f_{i}$ represents the fraction consumed by herbivores of each food item encountered; for cases where $f_{i}<1$ then $f_{i}=0.2$. Bar heights depict means, and error bars are 95\% confidence limits, over 1000 simulations.

(Figure 2). In several cases, in particular amongst spotted hyaena, fecal isotopic variability was as broad as the combined total variability across multiple herbivore species. Consequently, the inferred prey base of carnivores was generally more diverse and evenly spread across food items than it was for herbivores. Spotted hyaena, in particular, displayed an even spread of diets across individual fecal samples: the frequency occurrences of browsers:intermediate-feeders:grazers in hyaena diets were 3:4:2 and 1:4:2 for populations from the North and South of KNP, respectively (Figures 3A,B). Similarly, spotted hyaena specimens from WPGR showed diverse diets across individuals (0:5:2; Figure 3C). One carnivore, the lion (specimens from South KNP), showed very limited diversity in prey consumed, with all six specimens having $\delta^{13} \mathrm{C}$ values consistent with a diet comprising only intermediate-feeders. This is probably because all of these specimens were collected from the same locality in the field on the same day, and likely represent the most recent feeding activities of a single pride sharing kills. Herbivores, by contrast, typically focused their foraging activities either on $\mathrm{C}_{3}$-items (in browsers like kudu, Tragelaphus strepsiceros, and giraffe, Giraffa camelopardalis) or $\mathrm{C}_{4}$-grass (in grazers), with few differences across individuals. In both 


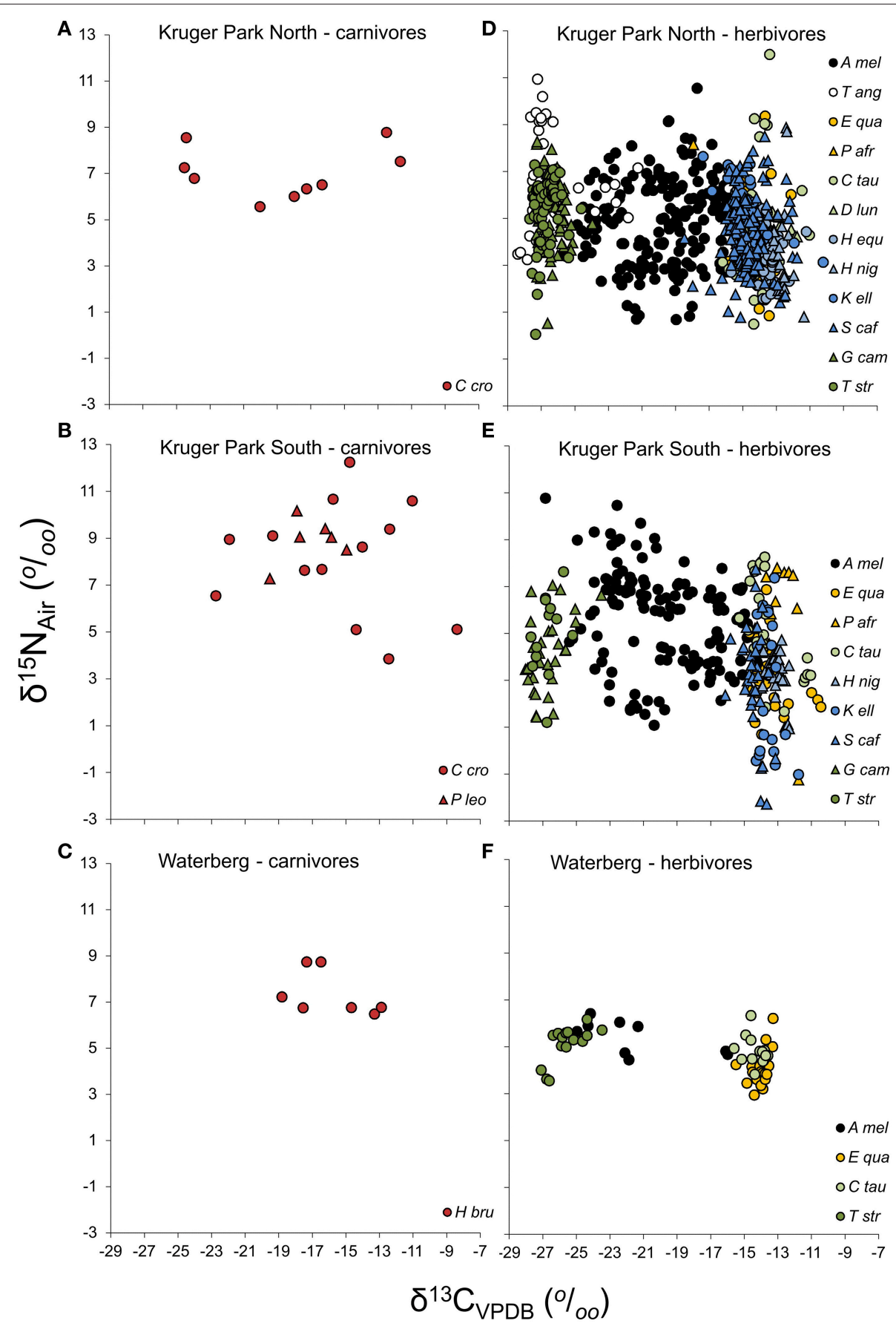

FIGURE 2 | Stable carbon and nitrogen isotope values of carnivore (A-C) and herbivore (D-F) feces from Kruger Park and Welgevonden Private Game Reserve in the Waterberg. See Table 1 for full species names.

guilds, preferred diets were evident in $\sim 95-100 \%$ of individuals sampled, with two exceptions, both at WPGR, where mixedfeeding was evident in 28 and $47 \%$ of individuals of grazing Plain's zebra (Equus quagga) and blue wildebeest (Connochaetes taurinus), respectively. Impala (Aepyceros melampus) diets were the most diverse of all herbivores sampled (6:166:25, 11:111:6, and 4:5:1 for KNP North, KNP South, and WPGR, respectively).
Impala diets are known to range from pure browsing to pure grazing, and anything inbetween, depending on local habitat conditions and changes in resource availability (e.g., Skinner and Smithers, 1990). Even in this species, though, the distribution of feeding styles was less diverse than was found for the spotted hyaena, since almost all individuals $(\sim 85 \%)$ had mixed diets, and the carbon isotope IQR was less than that of hyaenas from 
KNP North and similar to that of hyaenas from KNP South (Figures 4A,B). In WPGR, however, carbon isotope variability of the impala sample was higher than that observed in the brown hyaena.

Isotopic variability (interquartile ranges, IQRs) in both $\delta^{13} \mathrm{C}$ and $\delta^{15} \mathrm{~N}$ values showed a clear asymptotic pattern when plotted as a function of sample size in almost all populations sampled (Figure 4). Thus, despite the small sample sizes for many populations in our dataset, particularly carnivores, we can be confident that our data reflects overall population variability, validating comparisons across them. Exceptions are both warthog (Phacochoerus africanus) populations from KNP and, more importantly, the brown hyaena sample from WPGR, implying that the isotopic niche breadth of these populations is likely higher than recorded here. An emergent pattern in these analyses is that the carbon isotopic niche breadths for spotted hyaena populations remained higher than those of herbivores even when comparing samples of similar sizes (Figures 4A,B). Even the lion sample, despite comprising a single group of individuals from the same time, remained more carbonisotopically variable than most herbivores, as did the brown hyaena sample at WPGR (Figure 4C).

The combined isotopic niche variability within populations, measured as the standard ellipse areas (SEAc) in carbon and nitrogen isotope bi-space, was almost always higher for carnivores than herbivores (Figures 5A-C). Hyaenas had significantly (i.e., $>95 \%$ probability over $10^{4}$ permutations) higher SEAc than all herbivore species within each assemblage, with the exception of intermediate-feeding herbivores, impala, and nyala (Tragelaphus angasii) in the KNP North and WPGR assemblages. However, it must be emphasized that even in these cases, the evenness of distribution of feeding styles across individuals was lower in herbivores (Figure 3). Moreover, isotopic differences between individuals within populations, estimated from mean Euclidean distances between individual pairs, were significantly higher for hyaenas compared with all herbivore populations (Figures 5D-F). The only exception to this trend was that average inter-individual differences were higher for impala than brown hyaena at WPGR (Figure 5F). Inter-individual differences in the lion sample were similar to, or in some cases lower than, levels found in sympatric herbivores (Figure 5E).

\section{Longer Term Profiles}

Although longer-term carbon isotope profiles derived from serial analysis of teeth and hair are represented by a very small sample, and must be regarded in a very preliminary capacity. Nevertheless, these data do support the general hypothesis that individual-level dietary niche differences are rare amongst large-bodied herbivores. Amongst grazers, withinindividual effects account for $78 \%$ of the total variance in the data (Figure 6A), suggesting that inter-individual variability across individuals is too low to be a major factor driving foraging strategies even across species and across populations. For intermediate-feeders, tooth profiles from two individual springbok (Antidorcas marsupialis) from the Kalahari are isotopically similar (Bonferonni $p=0.278$ ), but both differ from

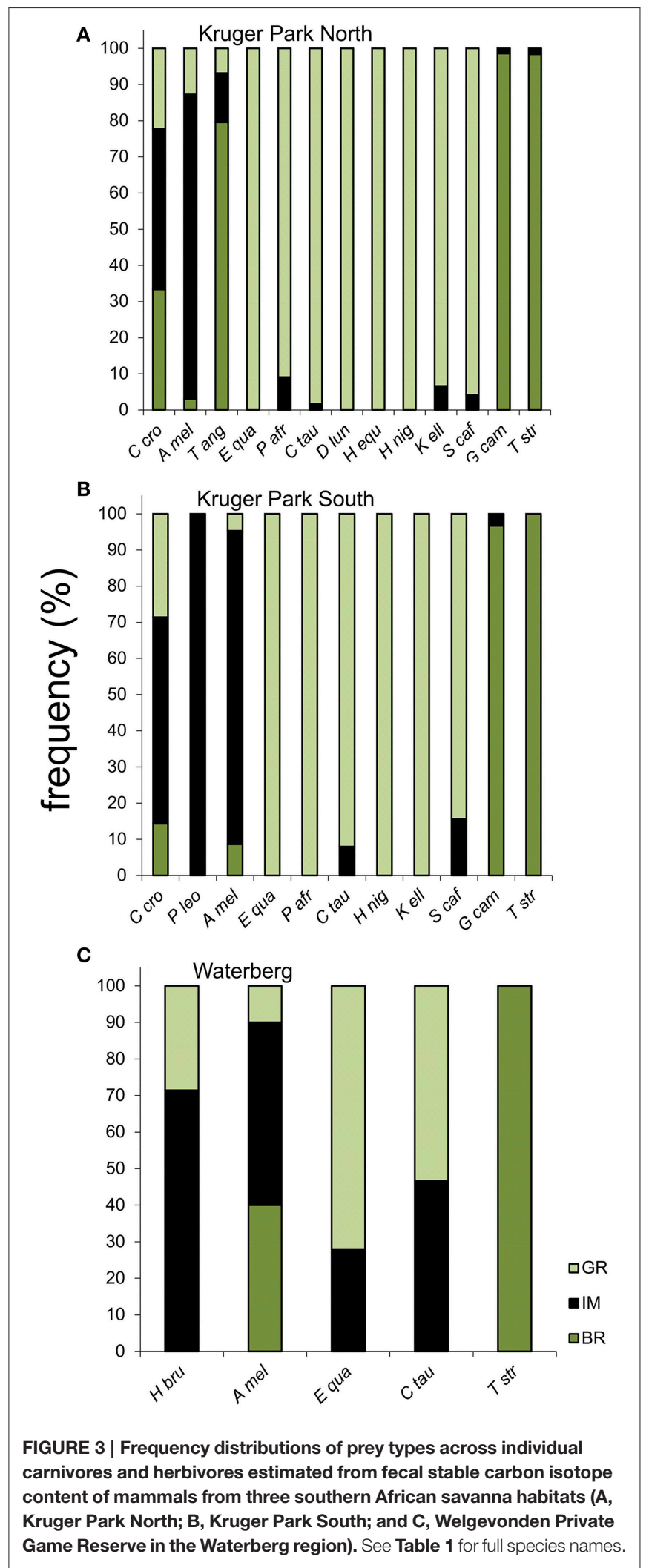

a single individual sourced from the grassland savanna of the central interior of the country ( $p<0.0001$; Figure 6B), implying lower levels of within- than between-population variation. Hair 


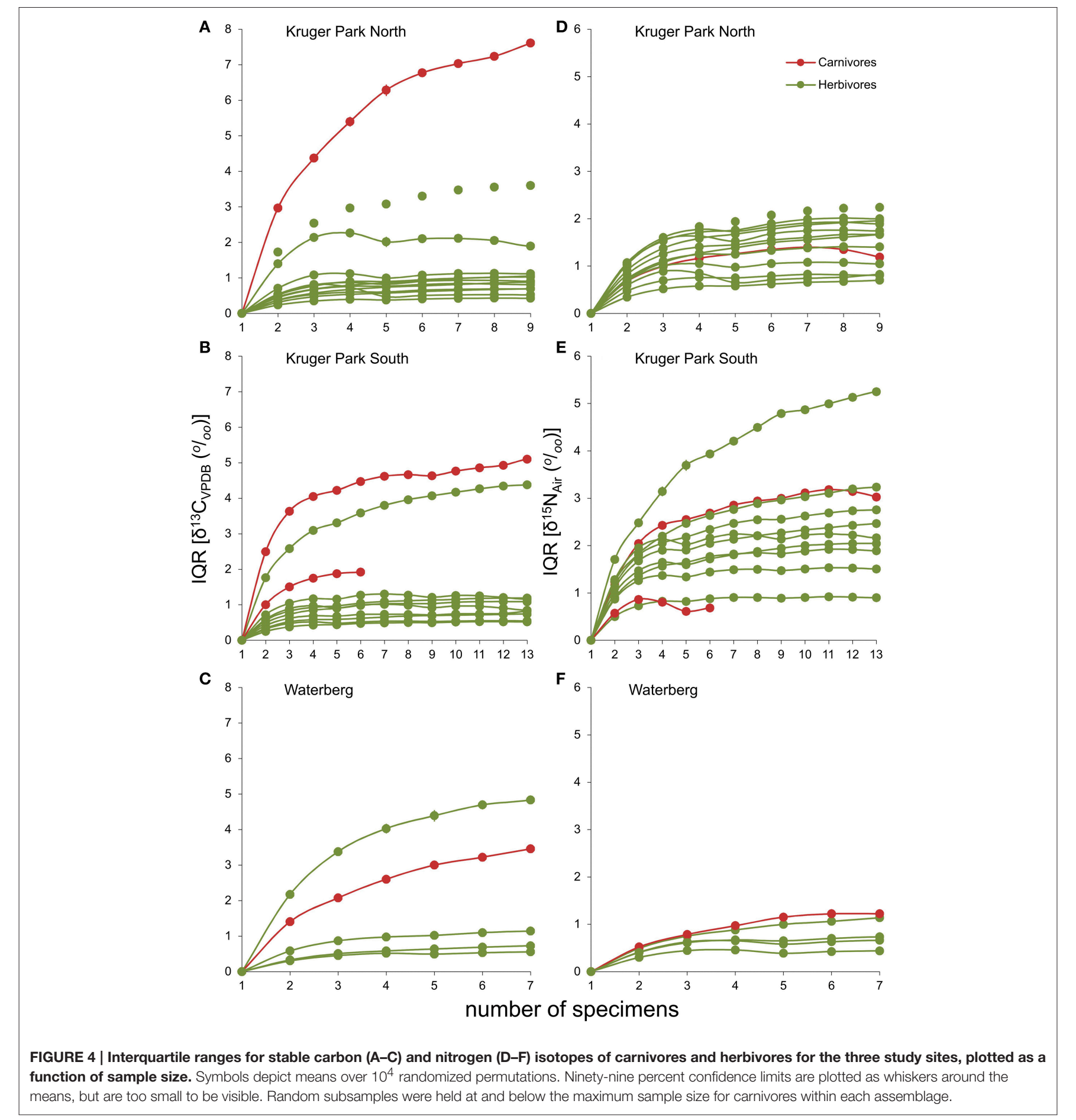

profiles of baboons from WPGR also showed higher levels of within- than between-individual isotopic variance $(95 \%$ of variance explained by within-individual effects; Figure 6C).

\section{DISCUSSION}

Phenotypic variation is an inherent feature within natural populations, and is the essential ingredient for evolution by natural selection (Darwin, 1859). The variation in dietary niches within such populations has emerged as an important focal point for discussion amongst evolutionary ecologists because such variation is almost certainly linked to individual fitness and associated selection processes (Bolnick, 2004; Pfennig et al., 2007, 2010; Araújo et al., 2011; Bolnick et al., 2011; Newsome et al., 2015). However, the ecological driversand fitness consequences-of within-population dietary niche variability are presently poorly understood (Araújo et al., 

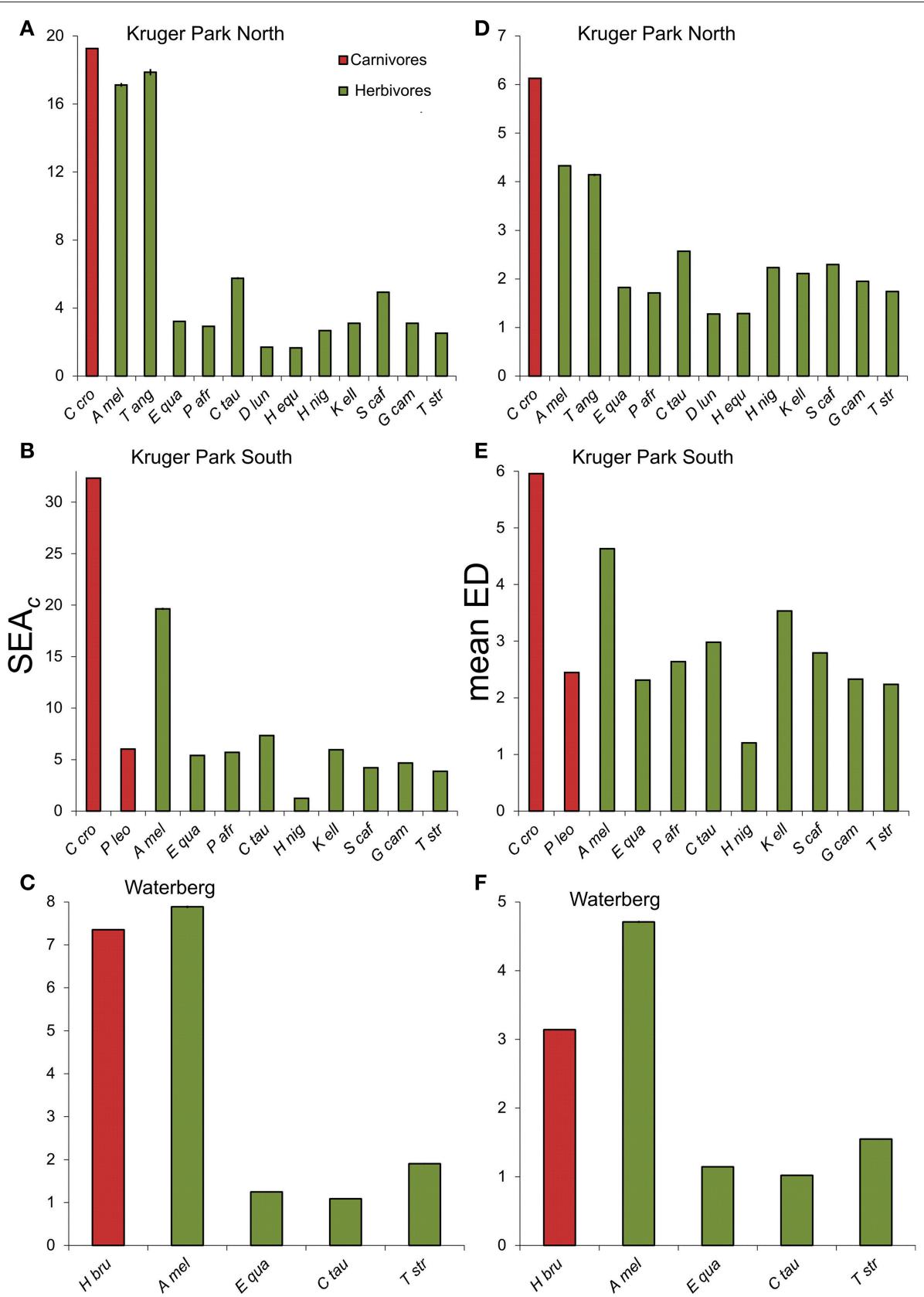

FIGURE 5 | Isotopic variability in carnivore and herbivore populations, measured as standard ellipse areas (SEAc) in carbon and nitrogen isotope bi-space (A-C), and as mean Euclidean Distances (ED) between pairs of individuals (D-F). Bar heights and error bars depict means and $95 \%$ confidence limits from $10^{4}$ randomized permutations (random subsamples were held at and below the maximum sample size for carnivores within each assemblage).

2011). In this study, we interrogated isotopic ( dietary) niche variation within populations of large-bodied mammalian carnivores and herbivores. The relative simplicity of food chains within these systems means that variations within trophic levels are easily traced using stable isotope approaches, with few of the confounding effects that could arise from added variation in systems with multiple and more complex trophic linkages (Vander Zanden and Rasmussen, 1999; Vander Zanden et al., 1999; Kaehler et al., 2000). Thus, we are also able to hypothesize potential differences in patterns of intrapopulation variation across trophic levels, thereby building toward a clearer understanding of factors that drive these trends in nature. Our prediction was that carnivore populations are more likely to display niche variability between individuals than herbivore populations, given the foraging effort associated with the high absolute food intake requirements of herbivores. Results of a 


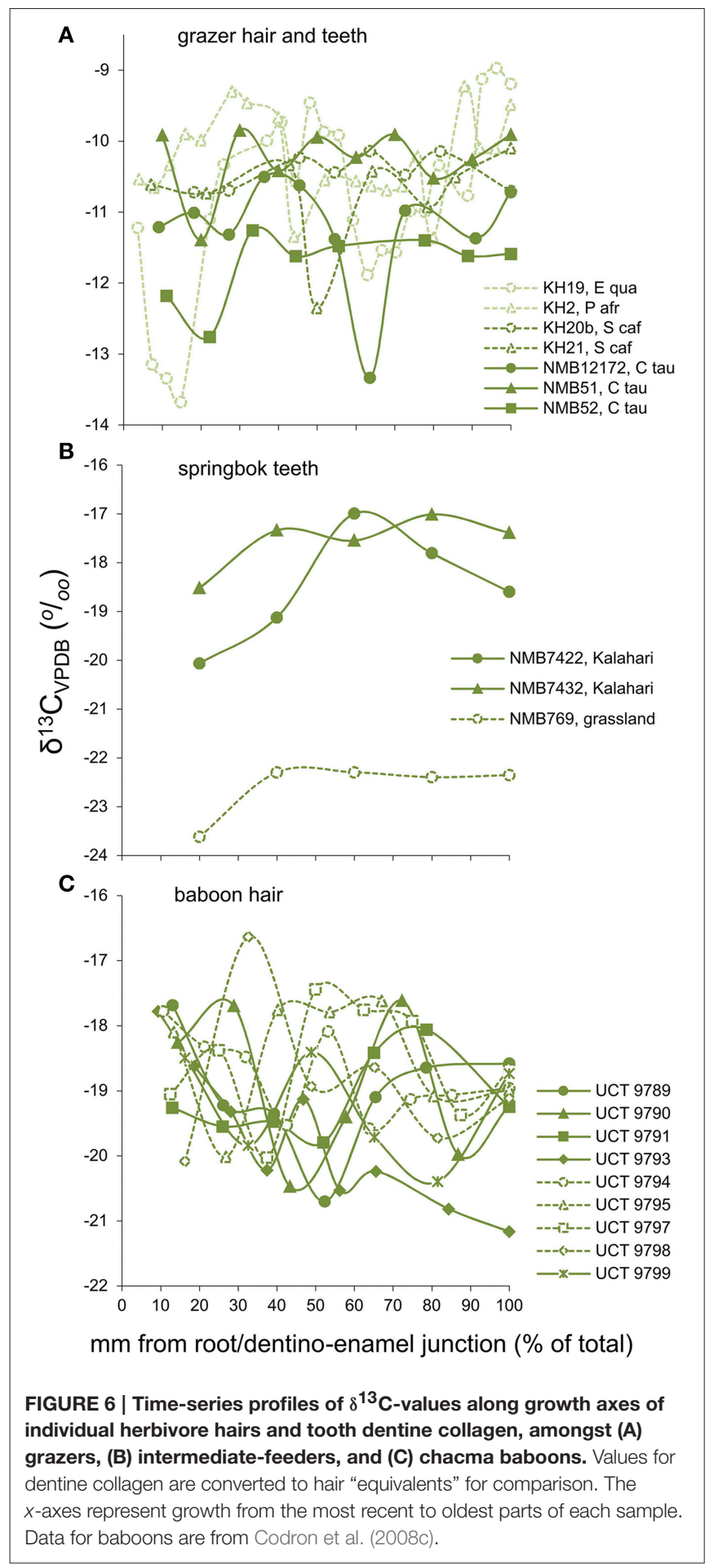

simplistic modeling simulation, supports this general prediction, revealing that inter-individual niche variation is more costly for large-bodied herbivores than for carnivores. Moreover, these results predicted that whereas individual specialization within carnivore populations can alleviate competition pressure by reducing levels of niche overlap, no such ecological advantage emerged for herbivores. In our analysis of a substantial fecal isotope dataset, we found that amongst large-bodied mammals in African savannas, carnivores generally had broader isotopic niche breadths, and that isotopic variability between individuals was generally greater within carnivore populations than in herbivore populations. Although these two phenomena are not necessarily related, it seems likely that the more generalist feeding behavior of carnivores allows for more opportunity for developing individualized dietary niches. These findings support previous assertions that both competition for resources and ecological opportunity contribute to differences in dietary niches between individuals within populations (Araújo et al., 2011; Robertson et al., 2015).

The small sample for carnivores is a limitation of this study worth discussing. Although, our analytical approaches took uneven sample sizes into consideration, we are almost certain that the complete level of population variability for both the lion and brown hyaena sample is underrepresented in our data. That being the case, it is likely that isotopic niche variation within carnivore populations is probably broader than presented here. Nonetheless, the small and unbalanced sample available to us means that comparisons across trophic levels must be treated and interpreted with some degree of caution. Clearly, much more isotopic data for African savanna carnivores, associated with data for available herbivore prey within assemblages, is needed.

Our data are also limited in that only short-term comparisons across individuals can be made using fecal isotope records. Hence, we do not know whether differences observed persist through time, or whether individuals from either trophic level switched their diets regularly so that individual dietary niches ultimately overlapped. The small sample of longer-term carbon isotope profiles presented in Figure 6 supports our conclusions, but is too small to be considered a thorough test of all hypotheses raised here. Similarly, published isotopic time series for individual African elephants (Codron et al., 2012b, 2013a), forest hogs (Hylochoerus meinertzhageni; $n=3$; Cerling and Viehl, 2004), oryx (Oryx gazelle), and springbok (Lehmann et al., 2013, 2015) have revealed much higher levels of withinthan between-individual isotope niche variability amongst herbivores. Nevertheless, until more longitudinal records of isotopic variability for a wider variety of species of both carnivores and herbivores are available, we can only conclude that overall isotopic niche variability, and the opportunity for individual specialization, is higher for carnivores than it is for herbivores.

Differentiating food items of consumers across $\mathrm{C}_{3^{-}}, \mathrm{C}_{4^{-}}$ , or mixed-prey (i.e., browser-, grazer-, or mixed-prey bases) items is a powerful heuristic approach to questions related to feeding ecology in savanna mammal systems, and is well within the realm of potential applications of stable isotope studies (Cerling et al., 2003; Sponheimer et al., 2003a). However, more subtle differences in diet, e.g., identifying prey items at species-level, and indeed in other behaviors, cannot be accounted for using this approach. This may be less of a constraint for investigations of herbivore niche variability since, given their high intake requirements, they tend to integrate local vegetation with a fairly low, albeit not entirely insignificant, degree of selectivity (Witt et al., 1998). Indeed, subtle differences 
in within-browse (foliage vs. fruit or bark) and within-grass (low-level lawn vs. taller fibrous grasses) diet compositions of herbivores are known in savanna systems (Bell, 1971; Murray and Illius, 2000), and interspecific resource partitioning at this level have previously been described through combined stable carbon and nitrogen isotope analysis (Codron et al., 2008b; Codron and Codron, 2009). Further work is needed to determine whether such differences occur at intra-population levels as well. For carnivores, isotopic similarity across prey species within browsing and grazing guilds, coupled with the fact that they ingest multiple body tissues with often vastly variable isotope compositions (due to isotope fractionation and turnover that occurs within different tissue types), makes it difficult to resolve carnivore diets at fine taxonomic levels. In other systems, diets of large-bodied carnivores have been resolved at species level, such as for the gray wolf (Canis lupus) from boreal forests in Canada (Urton and Hobson, 2005). However, in that case, standard deviations of isotope compositions of several prey species were higher than the range of mean values measured across the entire assemblage, casting doubt on the validity of the results of the mixing models used. Isotope-based reconstructions of carnivore diets have been more successful when the diversity of major prey items is small and/or detailed data on territories, available prey abundances, and other ecological parameters are available (Newsome et al., 2009; Robertson et al., 2015). Refining isotope-based diet reconstructions for carnivores will also require comparisons of isotope data with independent evidence, such as that obtained from analyses of scat (e.g., Avenant and Nel, 1997) or kill data for known individuals (e,g, Radloff and Du Toit, 2004).

In developing a conceptual framework for patterns of niche variability within populations, we focused almost entirely on a single constraint, i.e., absolute food intake requirements of carnivores and herbivores. Building a more realistic and cohesive model to capture predicted patterns would require incorporation of a number of additional factors that operate on the level of the individual. For one, it is well-known that herbivores require a diversity of prey (forage) types to maintain required nutrient uptake levels, and also that they often need to diversify their prey base in order to avoid overdosing on one species or type of plant secondary compound (Freeland and Janzen, 1974; Dearing et al., 2000; Provenza et al., 2003; Sorensen et al., 2005). These factors would almost certainly predict an even lesser degree of interindividual niche specialization in herbivores. It is also likely that body size plays a significant role. In our simulations, required foraging effort decreased with body size (Figure 1B). This occurred because intake scales with body mass ${ }^{\sim 0.75}$, meaning that larger animals have relatively lower intake requirements, and also because they ate larger prey items. The result may reflect the fact that smaller animals perceive a more fine-grained matrix (e.g., Begon et al., 2006), and thus encounter a wider diversity of prey types, than larger ones. Indeed, high energetic costs of foraging on very small prey is known to limit dietary niche breadths of large mammalian carnivores, especially those larger than $\sim 20 \mathrm{~kg}$ for which foraging on very small prey such as invertebrates becomes unfeasible (Carbone et al., 2007). But at very small body sizes, the fine-grained environments perceived by predators could afford further ecological opportunity for specialization at individual level, even for herbivores, as has been found for woodrats Neotoma fuscipes (McEachern et al., 2006).

One recent study reportedly found substantial inter-individual isotopic variability across herbivore individuals in two speciesthe springbok and oryx, using profiles of hairs sampled in the hyperarid Kunene region of Namibia (Lehmann et al., 2015). However, in that study, within-individual variation still accounted for more of the total variance observed than did between-individual effects (see above). Further, isotopic differences between individuals were usually too small to represent actual dietary differences $(<1 \%$, well within the range of $\mathrm{C}$ isotope variation that exists within single plant species, or even within individual plants), and were even smaller when the analysis was restricted to comparisons of individuals from the same locality (Lehmann et al., 2015).

The apparent lack of dietary niche specialization achievable by individuals within herbivore populations raises an interesting evolutionary question about the origins of the distinct feeding styles that exist today, and that are known from studies of fossil herbivores. Assuming that intermediate-feeding represents the primitive state for this group of animals (DeMiguel et al., 2008), diversification into distinct and more specialized trophic guilds (browsers or grazers) would have happened more recently in evolutionary time. Indeed, such directional shifts in diet within herbivore lineages have been shown using carbon isotope analysis of fossil mammal herbivores from the central interior of South Africa, from around 1 million years ago to the present (Codron et al., 2008a), and from the Turkana Basin in East Africa, from $\sim 4$ to 1 million years ago (Cerling et al., 2015). If herbivores had the opportunity for individual-level niche specialization, we might predict that at some point in the past, certain individuals within intermediate-feeding populations became more specialized on either grass or browse foods, leading, ultimately, toward the evolution of specialized feeding guilds. Were opportunities for specialization greater for herbivores in the past than they are today, or were evolutionary shifts toward more specialized feeding merely the result of environmental changes and changes in resource availability over geological time? This question is clearly important for understanding recent innovations in herbivore evolution, and should be readily answered by isotope tooth profiles in fossil individuals.

That herbivores appear to lack individual diet separation to a large degree does not mean carnivores will necessarily be individual specialists. It does mean, however, that carnivores should display this pattern more frequently. However, studies of this phenomenon must consider that many carnivore species are highly territorial and so each individual may have access to only a fraction of the total prey population (and the same may also apply to herbivore species that display varying degrees of territoriality). Therefore, arising differences between individuals will need to be compared to changes in prey availability across territories, and interpretations should consider whether observed individual-level dietary differences are merely a manifestation of territorial behavior. In addition, 
while the solitary behavior of many carnivores may increase the opportunity for individual specialization, species that hunt in packs are more likely to specialize at this level rather than the level of the individual (Urton and Hobson, 2005). As previous authors have noted, a more detailed understanding of the causes and consequences of within-population diet niche variability will likely elucidate ecological mechanisms for natural selection. However, reaching this understanding will require further comparisons between populations with higher- vs. lowerlevels of both total population and within-population dietary niche variation. Given expected differences between carnivores and herbivores, large-bodied mammal assemblages provide a clear example of a system in which such comparisons can be made.

\section{AUTHOR CONTRIBUTIONS}

DC co-developed the concept, carried out simulations, data analyses and coding, wrote the manuscript. JC co-developed the concept, co-wrote early drafts of the manuscript. MS produced parts of the isotope database used, discussed development of main concept and applicability of fecal data to this, edited main text. MC produced carnivore and herbivore intake datasets, proposed concept of constraints related to encounter rate, edited main text.

\section{REFERENCES}

Ambrose, S. H., and Norr, L. (1993). "Experimental evidence for the relationship of the carbon isotope ratios of whole diet and dietary protein to those of bone collagen and carbonate," in Prehistoric Human Bone: Archaeology at the Molecular Level, eds J. B. Lambert and G. Grupe (Berlin: SpringerVerlag), 1-37.

Ambrose, S. H. (1991). Effects of diet, climate and physiology on nitrogen isotope abundances in terrestrial foodwebs. J. Archaeol. Sci. 18, 293-317. doi: 10.1016/0305-4403(91)90067-Y

Araújo, M., Bolnick, D., Machado, G., Giaretta, A., and Dos Reis, S. (2007). Using $\delta^{13} \mathrm{C}$ stable isotopes to quantify individual-level diet variation. Oecologia 152, 643-654. doi: 10.1007/s00442-007-0687-1

Araújo, M. S., Bolnick, D. I., and Layman, C. A. (2011). The ecological causes of individual specialisation. Ecol. Lett. 14, 948-958. doi: 10.1111/j.14610248.2011.01662.x

Avenant, N. L., and Nel, J. A. J. (1997). Prey use by four syntopic carnivores in a strandveld ecosystem. South Afr. J. Wildlife Res. 27, 86-93.

Begon, M., Townsend, C. R., and Harper, J. L. (2006). Ecology, from Individuals to Ecosystems, 4th Edn. Oxford: Blackwell Publishing.

Bell, R. H. V. (1971). A grazing ecosystem in the Serengeti. Sci. Am. 225, 86-93. doi: 10.1038/scientificamerican0771-86

Ben-David, M., and Flaherty, E. A. (2012). Stable isotopes in mammalian research: a beginner's guide. J. Mammal. 93, 1409-1416. doi: 10.1644/11-MAMM-S166.1

Ben-David, M., Flynn, R. W., and Schell, D. M. (1997). Annual and seasonal changes in diets of martens: evidence from stable isotope analysis. Oecologia 111, 280-291. doi: 10.1007/s004420050236

Bolnick, D. I., Amarasekare, P., Araújo, M. S., Bürger, R., Levine, J. M., Novak, M., et al. (2011). Why intraspecific trait variation matters in community ecology. Trends Ecol. Evol. 26, 183-192. doi: 10.1016/j.tree.2011.01.009

Bolnick, D. I., Svanbäck, R., Araújo, M. S., and Persson, L. (2007). Comparative support for the niche variation hypothesis that more generalized populations also are more heterogeneous. Proc. Natl. Acad. Sci. U.S.A. 104, 10075-10079. doi: $10.1073 /$ pnas. 0703743104

\section{FUNDING}

National Research Foundation (91599); Palaeontological Scientific Trust; DST/NRF Centre of Excellence in Palaeosciences.

\section{ACKNOWLEDGMENTS}

This research was funded by the National Research Foundation of South Africa (African Origins Platform, grant 91599, DC), the Palaeontological Scientific Trust (PAST, DC, and JC), and the DST/NRF Centre of Excellence in Palaeosciences, University of the Witwatersrand (JC). We thank the numerous conservation authorities which have facilitated our fieldwork in South African savannas, in particular SANParks and the management team of Welgevonden Private Game Reserve, and John Lanham and Ian Newton for assistance with stable isotope analysis. Our study profited greatly from discussions with Julia Lee-Thorp, Judith Sealy, Norman Owen-Smith, James Brink, Thure Cerling, Frans Radloff, Rina Grant, and Darryl de Ruiter, who have willingly shared their insights into stable isotope ecology and the behavioral ecology of savanna mammals. We thank Waldo Bekker and Erin Wreford for the herbivore tail hair sample collected to date. Three reviewers commented on this manuscript and aided in improving the quality of the final product.

Bolnick, D. I., Svanbäck, R., Fordyce, J. A., Yang, L. H., Davis, J. M., Hulsey, C. D., et al. (2003). The ecology of individuals: incidence and implications of individual specialization. Am. Nat. 161, 1-28. doi: 10.1086/343878

Bolnick, D. I. (2004). Can intraspecific competition drive disruptive selection? An experimental test in natural populations of sticklebacks. Evolution 58, 608-618. doi: 10.1111/j.0014-3820.2004.tb01683.x

Botha, M. S., and Stock, W. D. (2005). Stable isotope composition of faeces as an indicator of seasonal diet selection in wild herbivores in southern Africa. S. Afr. J. Sci. 101, 371-374.

Bourliére, F. (1975). "Mammals, small and large: the ecological implications of size," in Small Mammals: Their Productivity and Population Dynamics, eds F. B. Golley, K. Petrusewicz, and L. Ryszkowski (Cambridge: Cambridge University Press), 1-8.

Brose, U., Jonsson, T., Berlow, E. L., Warren, P., Banasek-Richter, C., Bersier, L.F., et al. (2006). Consumer-resource body-size relationships in natural food webs. Ecology 87, 2411-2417. doi: 10.1890/0012-9658(2006)87[2411:CBRINF] 2.0.CO;2

Carbone, C., Mace, G. M., Roberts, S. C., and Macdonald, D. W. (1999). Energetic constraints on the diet of terrestrial carnivores. Nature 402, 286-288. doi: $10.1038 / 46266$

Carbone, C., Teacher, A., and Rowcliffe, J. M. (2007). The costs of carnivory. PLoS Biol. 5:e22. doi: 10.1371/journal.pbio.0050022

Cerling, T. E., Andanje, S. A., Blumenthal, S. A., Brown, F. H., Chritz, K. L., Harris, J. M., et al. (2015). Dietary changes of large herbivores in the Turkana Basin, Kenya from 4 to 1 Ma. Proc. Natl. Acad. Sci. U.S.A. 112, 11467-11472. doi: $10.1073 /$ pnas. 1513075112

Cerling, T. E., and Harris, J. M. (1999). Carbon isotope fractionation between diet and bioapatite in ungulate mammals and implications for ecological and paleoecological studies. Oecologia 120, 347-363. doi: 10.1007/s004420050868

Cerling, T. E., Harris, J. M., and Passey, B. H. (2003). Diets of East African Bovidae based on stable isotope analysis. J. Mammal. 84, 456-470. doi: 10.1644/15451542(2003)084<0456:DOEABB >2.0.CO;2

Cerling, T. E., and Viehl, K. (2004). Seasonal diet changes of the forest hog (Hylochoerus meinertzhageni) based on the carbon isotopic composition of hair. Afr. J. Ecol. 42, 88-92. doi: 10.1111/j.1365-2028.2004.00500.x 
Cerling, T. E., Wittemyer, G., Rasmussen, H. B., Vollrath, F., Cerling, C. E., Robinson, T. J., et al. (2006). Stable isotopes in elephant hair documents migration patterns and diet changes. Proc. Natl. Acad. Sci. U.S.A. 103, 371-373. doi: 10.1073/pnas.0509606102

Cherel, Y., Kernaléguen, L., Richard, P., and Guinet, C. (2009). Whisker isotopic signature depicts migration patterns and multi-year intra- and inter-individual foraging strategies in fur seals. Biol. Lett. 5, 830-832. doi: $10.1098 / \mathrm{rsbl} .2009 .0552$

Clauss, M., Kaiser, T. M., and Hummel, J. (2008). "The morphophysiological adaptations of browsing and grazing mammals," in The Ecology of Browsing and Grazing, eds I. J. Gordon and H. H. T. Prins (Heidelberg: Springer), 149-178.

Clauss, M., Schwarm, A., Ortmann, S., Streich, W. J., and Hummel, J. (2007). A case of non-scaling in mammalian physiology? Body size, digestive capacity, food intake, and ingesta passage in mammalian herbivores. Comp. Biochem. Physiol. A 148, 249-265. doi: 10.1016/j.cbpa.2007.05.024

Codron, D., Brink, J. S., Rossouw, L., and Clauss, M. (2008a). The evolution of ecological specialization in southern African ungulates: competition or physical environmental turnover? Oikos 117, 344-353. doi: 10.1111/j.2007.00301299.16387.x

Codron, D., Brink, J. S., Rossouw, L., Clauss, M., Codron, J., Lee-Thorp, J. A., et al. (2008b). Functional differentiation of African grazing ruminants: an example of specialized adaptations to very small changes in diet. Biol. J. Linnaean Soc. 94, 755-764. doi: 10.1111/j.1095-8312.2008.01028.x

Codron, D., and Codron, J. (2009). Reliability of $\delta^{13} \mathrm{C}$ and $\delta^{15} \mathrm{~N}$ in faeces for reconstructing savanna herbivore diet. Mamm. Biol. 74, 36-48. doi: 10.1016/j.mambio.2007.12.005

Codron, D., Codron, J., Lee-Thorp, J. A., Sponheimer, M., and De Ruiter, D. (2005a). Animal diets in the Waterberg based on stable isotopic composition of faeces. S. Afr. J. Wildl. Res. 35, 43-52. doi: 10.5167/uzh-25362

Codron, D., Codron, J., Lee-Thorp, J. A., Sponheimer, M., De Ruiter, D., and Brink, J. S. (2006). Dietary variation in impala Aepyceros melampus recorded by carbon isotope composition of feces. Acta Zool. Sin. 52, 1015-1025. doi: $10.5167 /$ uzh-25360

Codron, D., Codron, J., Lee-Thorp, J. A., Sponheimer, M., De Ruiter, D., and Brink, J. S. (2007a). Stable isotope characterization of mammalian predatorprey relationships in a South African savanna. Eur. J. Wildl. Res. 53, 161-170. doi: 10.1007/s10344-006-0075-x

Codron, D., Codron, J., Lee-Thorp, J. A., Sponheimer, M., De Ruiter, D., Sealy, J., et al. (2007b). Diets of savanna ungulates from stable carbon isotope composition of faeces. J. Zool. (Lond.) 273, 21-29. doi: 10.1111/j.14697998.2007.00292.x

Codron, D., Codron, J., Sponheimer, M., Bernasconi, S. M., and Clauss, M. (2011a). When animals are not quite what they eat: diet digestibility influences ${ }^{13} \mathrm{C}$ incorporation rates and apparent discrimination in a mixed-feeding herbivore. Can. J. Zool. 89, 453-465. doi: 10.1139/z11-010

Codron, D., Codron, J., Sponheimer, M., Lee-Thorp, J. A., Robinson, T., Grant, C. C., et al. (2005b). Assessing diet in savanna herbivores using stable carbon isotope ratios of faeces. Koedoe 48, 115-124. doi: 10.4102/koedoe.v48i1.170

Codron, D., Hull, J., Brink, J. S., Codron, J., Ward, D., and Clauss, M. (2011b). Influence of competition on niche dynamics of syntopic grazing ungulates: contrasting the predictions of habitat selection models using stable isotope analysis. Evol. Ecol. Res. 13, 217-235.

Codron, D., Lee-Thorp, J. A., Sponheimer, M., De Ruiter, D., and Codron, J. (2008c). What insights can baboon feeding ecology provide for early hominin niche differentiation? Int. J. Primatol. 29, 757-772. doi: 10.1007/s10764-0089261-x

Codron, D., Sponheimer, M., Codron, J., Newton, I., Lanham, J. L., and Clauss, M. (2012a). The confounding effects of source isotopic heterogeneity on consumer-diet and tissue-tissue stable isotope relationships. Oecologia 169, 939-953. doi: 10.1007/s00442-012-2274-3

Codron, J., Codron, D., Sponheimer, M., Kirkman, K., Duffy, K. J., Raubenheimer, E. J., et al. (2012b). Stable isotope series from elephant ivory reveal lifetime histories of a true dietary generalist. Proc. R. Soc. B Biol. Sci. 279, 2433-2441. doi: $10.1098 /$ rspb.2011.2472

Codron, J., Kirkman, K., Duffy, K. J., Sponheimer, M., Lee-Thorp, J. A., Ganswindt, A., et al. (2013a). Stable isotope turnover and variability in tail hairs of captive and free-ranging African elephants (Loxodonta africana) reveal dietary niche differences within populations. Can. J. Zool. 91, 124-134. doi: 10.1139/cjz2012-0155

Codron, J., Lee-Thorp, J. A., Sponheimer, M., and Codron, D. (2013b). Plant stable isotope composition across habitat gradients in a semi-arid savanna: implications for environmental reconstruction. J. Quaternary Sci. 28, 301-310. doi: 10.1002/jqs.2614

Cucherousset, J., Acou, A., Blanchet, S., Britton, J. R., Beaumont, W. R. C., and Gozlan, R. E. (2011). Fitness consequences of individual specialisation in resource use and trophic morphology in European eels. Oecologia 167, 75-84. doi: 10.1007/s00442-011-1974-4

Damuth, J. (1987). Interspecific allometry of population density in mammals and other animals: the independence of body mass and population energy-use. Biol. J. Linnaean Soc. 31, 193-246. doi: 10.1111/j.1095-8312.1987.tb01990.x

Darwin, C. (1859). On the Origin of Species by Means of Natural Selection. London: John Murray.

Dearing, M. D., Mangione, A. M., and Karasov, W. H. (2000). Diet breadth of mammalian herbivores: nutrient versus detoxification constraints. Oecologia 123, 397-405. doi: 10.1007/s004420051027

Dell Inc. (2015). STATISTICA 12. Tulsa, OK.

DeMiguel, D., Fortelius, M., Azanza, B., and Morales, J. (2008). Ancestral feeding state of ruminants reconsidered: earliest grazing adaptation claims a mixed condition for Cervidae. BMC Evol. Biol. 8:13. doi: 10.1186/1471-2148-8-13

Djagoun, C. M. S., Codron, D., Sealy, J., Mensah, G. A., and Sinsin, B. (2013). Stable carbon isotope analysis of the diets of West African bovids in Pendjari Biosphere Reserve, Northern Benin. S. Afr. J. Wildl. Res. 43, 33-43. doi: 10.3957/056.043.0107

Du Toit, J. T. (2003). "Large herbivores and savanna heterogeneity," in The Kruger Experience: Ecology and Management of Savanna Heterogeneity, eds J. T. Du Toit, K. H. Rogers and H. C. Biggs (Washington, DC: Island Press), 292-309.

Freeland, W. J., and Janzen, D. H. (1974). Strategies in herbivory in mammals: the role of plant secondary compounds. Am. Nat. 108, 269-289. doi: $10.1086 / 282907$

Gagnon, M., and Chew, A. E. (2000). Dietary preferences in extant African Bovidae. J. Mammal. 81, 490-511. doi: 10.1644/1545-1542(2000)081<0490: $\mathrm{DPIEAB}>2.0 . \mathrm{CO} ; 2$

Gervasi, V., Nilsen, E. B., and Linnell, J. D. C. (2015). Body mass relationships affect the age structure of predation across carnivore-ungulate systems: a review and synthesis. Mamm. Rev. 45, 253-266. doi: 10.1111/mam.12047

Hayward, M. W., and Kerley, G. I. H. (2005). Prey preferences of the lion (Panthera leo). J. Zool. (Lond.) 267, 309-322. doi: 10.1017/S0952836905007508

Hofmann, R. R. (1973). The Ruminant Stomach. Nairobi: East African Literature Bureau.

Hofmann, R. R. (1989). Evolutionary steps of ecophysiological adaptation and diversification of ruminants: a comparative view of their digestive system. Oecologia 78, 443-457. doi: 10.1007/BF00378733

Illius, A. W., and Gordon, I. J. (1987). The allometry of food intake in grazing ruminants. J. Anim. Ecol. 56, 989-999. doi: 10.2307/4961

Jackson, A. L., Inger, R., Parnell, A. C., and Bearhop, S. (2011). Comparing isotopic niche widths among and within communities: SIBER - Stable Isotope Bayesian Ellipses in R. J. Anim. Ecol. 80, 595-602. doi: 10.1111/j.1365-2656.2011.01806.x

Kaehler, S., Pakhomov, E. A., and Mcquaid, C. D. (2000). Trophic structure of the marine foodweb at the Prince Edward Islands (Southern Ocean) determined by $\delta^{13} \mathrm{C}$ and $\delta^{15} \mathrm{~N}$ analysis. Mar. Ecol. Prog. Ser. 208, 13-20. doi: 10.3354/meps 208013

Koch, P. L., Heisinger, J., Moss, C., Carlson, R. W., Fogel, M. L., and Behrensmeyer, A. K. (1995). Isotopic tracking of change in diet and habitat use in African elephants. Science 267, 1340-1343. doi: 10.1126/science.267.5202.1340

Lee-Thorp, J. A., Sealy, J. C., and Van Der Merwe, N. J. (1989). Stable carbon isotope ratio differences between bone collagen and bone apatite, and their relationship to diet. J. Archaeol. Sci. 16, 585-599. doi: 10.1016/03054403(89)90024-1

Lehmann, D., Mfune, J. K. E., Gewers, E., Brain, C., and Voigt, C. C. (2015). Individual variation of isotopic niches in grazing and browsing desert ungulates. Oecologia 179, 75-88. doi: 10.1007/s00442-015-3335-1

Lehmann, D., Mfune, J. K. E., Gewers, E., Cloete, J., Brain, C., and Voigt, C. C. (2013). Dietary plasticity of generalist and specialist ungulates in the Namibian desert: a stable isotopes approach. PLoS ONE 8:e72190. doi: 10.1371/annotation/89fe804f-20cc-40cc-99af-d42751676d36 
McEachern, M. B., Eagles-Smith, C. A., Efferson, C. M., and Van Vuren, D. H. (2006). Evidence for local specialization in a generalist mammalian herbivore, Neotoma fuscipes. Oikos 113, 440-448. doi: 10.1111/j.2006.0030-1299.14176.x

Minagawa, M., and Wada, E. (1984). Stepwise enrichment of ${ }^{15} \mathrm{~N}$ along food chains: further evidence and the relation between $\delta^{15} \mathrm{~N}$ and animal age. Geochim. Cosmochim. Acta 48, 1135-1140. doi: 10.1016/0016-7037(84) 90204-7

Murray, M. G., and Illius, A. W. (2000). Vegetation modification and resource competition in grazing ungulates. Oikos 89, 501-508. doi: 10.1034/j.16000706.2000.890309.x

Newsome, S. D., Bentall, G. B., Tinker, M. T., Oftedal, O. T., Ralls, K., Estes, J. A., et al. (2010). Variation in $\delta^{13} \mathrm{C}$ and $\delta^{15} \mathrm{~N}$ diet-vibrissae trophic discrimination factors in a wild population of California sea otters. Ecol. Appl. 20, 1744-1752. doi: $10.1890 / 09-1502.1$

Newsome, S. D., Tinker, M. T., Gill, V. A., Hoyt, Z. N., Doroff, A., Nichol, L., et al. (2015). The interaction of intraspecific competition and habitat on individual diet specialization: a near range-wide examination of sea otters. Oecologia 178, 45-59. doi: 10.1007/s00442-015-3223-8

Newsome, S. D., Tinker, M. T., Monson, D. H., Oftedal, O. T., Ralls, K., Staedler, M. M., et al. (2009). Using stable isotopes to investigate individual diet specialization in California sea otters (Enhydra lutris nereis). Ecology 90, 961-974. doi: 10.1890/07-1812.1

Owen-Smith, N. (1997). Distinctive features of the nutritional ecology of browsing versus grazing ruminants. Z. Saugetierkd. 62, 176-191.

Passey, B. H., Robinson, T. F., Ayliffe, L. K., Cerling, T. E., Sponheimer, M., Dearing, M. D., et al. (2005). Carbon isotope fractionation between diet, breath CO2, and bioapatite in different animals. J. Archaeol. Sci. 32, 1459-1470. doi: 10.1016/j.jas.2005.03.015

Pfennig, D. W., Rice, A. M., and Martin, R. A. (2007). Field and experimental evidence for competition's role in phenotypic divergence. Evolution 61, 257-271. doi: 10.1111/j.1558-5646.2007.00034.x

Pfennig, D. W., Wund, M. A., Snell-Rood, E. C., Cruickshank, T., Schlichting, C. D., and Moczek, A. P. (2010). Phenotypic plasticity's impacts on diversification and speciation. Trends Ecol. Evol. 25, 459-467. doi: 10.1016/j.tree.2010.05.006

Phillips, D., Newsome, S., and Gregg, J. (2005). Combining sources in stable isotope mixing models: alternative methods. Oecologia 144, 520-527. doi: 10.1007/s00442-004-1816-8

Pianka, E. R. (1986). Ecology and Natural History of Desert Lizards. Princeton, NJ: Princeton University Press.

Provenza, F. D., Villalba, J. J., Dziba, L. E., Atwood, S. B., and Banner, R. E. (2003). Linking herbivore experience, varied diets, and plant biochemical diversity. Small Rumin. Res. 49, 257-274. doi: 10.1016/S0921-4488(03)00143-3

Radloff, F. G. T., and Du Toit, J. T. (2004). Large predators and their prey in a southern African savanna: a predator's size determines its prey size range. J. Anim. Ecol. 73, 410-423. doi: 10.1111/j.0021-8790.2004.00817.x

Radloff, F. G. T., Van Der Waal, C., and Bond, A. L. (2013). Extensive browsing by a conventional grazer? Stable carbon isotope analysis reveals extraordinary dietary flexibility among Sanga cattle of North Central Namibia. Isot. Environ. Health Stud. 49, 318-324. doi: 10.1080/10256016.2013.789025

Robbins, C., Felicetti, L., and Sponheimer, M. (2005). The effect of dietary protein quality on nitrogen isotope discrimination in mammals and birds. Oecologia 144, 534-540. doi: 10.1007/s00442-005-0021-8

Robertson, A., Mcdonald, R. A., Delahay, R. J., Kelly, S. D., and Bearhop, S. (2014). Individual foraging specialisation in a social mammal: the European badger (Meles meles). Oecologia 176, 409-421. doi: 10.1007/s00442-0143019-2

Robertson, A., Mcdonald, R. A., Delahay, R. J., Kelly, S. D., and Bearhop, S. (2015). Resource availability affects individual niche variation and its consequences in group-living European badgers Meles meles. Oecologia 178, 31-43. doi: $10.1007 / \mathrm{s} 00442-014-3202-5$

Skinner, J. D., and Smithers, R. H. N. (1990). The Mammals of the Southern African Subregion, 2nd Edn. Pretoria: University of Pretoria.

Sorensen, J., Heward, E., and Dearing, M. (2005). Plant secondary metabolites alter the feeding patterns of a mammalian herbivore (Neotoma lepida). Oecologia 146, 415-422. doi: 10.1007/s00442-005-0236-8

Sponheimer, M., Cerling, T. E., Robinson, T. F., Tegland, L., Roeder, B. L., Ayliffe, L., et al. (2006). Turnover of stable carbon isotopes in the muscle, liver and breath $\mathrm{CO}_{2}$ of alpacas (Lama pacos). Rapid Commun. Mass Spectrom. 20, 1395-1399. doi: $10.1002 / \mathrm{rcm} .2454$
Sponheimer, M., Lee-Thorp, J. A., De Ruiter, D. J., Smith, J. M., Van Der Merwe, N. J., Reed, K., et al. (2003a). Diets of southern African Bovidae: stable isotope evidence. J. Mammal. 84, 471-479. doi: 10.1644/15451542(2003)084<0471:DOSABS>2.0.CO;2

Sponheimer, M., Robinson, T., Ayliffe, L., Passey, B., Roeder, B., Shipley, L., et al. (2003b). An experimental study of carbon-isotope fractionation between diet, hair, and feces of mammalian herbivores. Can. J. Zool. 81, 871-876. doi: 10.1139/z03-066

Sponheimer, M., Robinson, T., Ayliffe, L., Roeder, B., Hammer, J., Passey, B., et al. (2003c). Nitrogen isotopes in mammalian herbivores: hair $\delta^{15} \mathrm{~N}$ values from a controlled feeding study. Int. J. Osteoarchaeol. 13, 80-87. doi: 10.1002/oa.655

Stephens, D. W., and Krebs, J. R. (1986). Foraging Theory. Princeton, NJ: Princeton University Press.

Tieszen, L., Hein, D., Qvortrup, D., Troughton, J., and Imbamba, S. (1979). Use of $\delta^{13} \mathrm{C}$ values to determine vegetation selectivity in east African herbivores. Oecologia 37, 351-359. doi: 10.1007/BF00347911

Tieszen, L. L., Boutton, T. W., Ottichilo, W. K., Nelson, D. E., and Brandt, D. H. (1989). An assessment of long-term food habits of Tsavo elephants based on stable carbon and nitrogen isotope ratios of bone collagen. Afr. J. Ecol. 27, 219-226. doi: 10.1111/j.1365-2028.1989.tb01015.x

Tieszen, L. L., Boutton, T. W., Tesdahl, K. G., and Slade, N. A. (1983). Fractionation and turnover of stable carbon isotopes in animal tissues: implications for $\delta^{13} \mathrm{C}$ analysis of diet. Oecologia 57, 32-37. doi: 10.1007/BF00379558

Urton, E., and Hobson, K. (2005). Intrapopulation variation in gray wolf isotope $\left(8^{15} \mathrm{~N}\right.$ and $\left.\delta^{13} \mathrm{C}\right)$ profiles: implications for the ecology of individuals. Oecologia 145, 316-325. doi: 10.1007/s00442-005-0124-2

Van Soest, P. J. (1994). Nutritional Ecology of the Ruminant. New York, NY: Comstock.

Van Valen, L. (1965). Morphological variation and width of ecological niche. Am. Nat. 99, 377-390. doi: 10.1086/282379

Vander Zanden, H. B., Bjorndal, K. A., and Bolten, A. B. (2013). Temporal consistency and individual specialization in resource use by green turtles in successive life stages. Oecologia 173, 767-777. doi: 10.1007/s00442-013-2655-2

Vander Zanden, H. B., Bjorndal, K. A., Reich, K. J., and Bolten, A. B. (2010). Individual specialists in a generalist population: results from a long-term stable isotope series. Biol. Lett. 6, 711-714. doi: 10.1098/rsbl.2010.0124

Vander Zanden, M. J., and Rasmussen, J. B. (1999). Primary consumer $\delta^{13} \mathrm{C}$ and $\delta^{15} \mathrm{~N}$ and the trophic position of aquatic consumers. Ecology 80, 1395-1404. doi: 10.1890/0012-9658(1999)080[1395:PCCANA]2.0.CO;2

Vander Zanden, M. J., Shuter, B. J., Lester, N., and Rasmussen, J. B. (1999). Patterns of food chain length in lakes: a stable isotope study. Am. Nat. 154, 406-416. doi: $10.1086 / 303250$

Venter, F. J., Scholes, R. J., and Eckhardt, H. C. (2003). "The abiotic template and its associated vegetation pattern," in The Kruger Experience: Ecology and Management of Savanna Heterogeneity, eds J. T. Du Toit, K. H. Rogers, and H. C. Biggs (Washington, DC: Island Press), 83-129.

Vogel, J. C., Fuls, A., and Ellis, R. P. (1978). The geographical distribution of Kranz grasses in South Africa. S. Afr. J. Sci. 74, 209-215.

Vogel, J. C. (1978). Isotopic assessment of the dietary habits of ungulates. S. Afr. J. Sci. 74, 298-301.

Whiten, A., Bryne, R. W., Barton, R. A., Waterman, P. G., and Henzi, S. P. (1991). Dietary and foraging strategies of baboons. Philos. Trans. R. Soc. Lond. B 334, 187-197. doi: 10.1098/rstb.1991.0108

Witt, G. B., Moll, E. J., Beeton, R. J. S., and Murray, P. J. (1998). Isotopes, wool, and rangeland monitoring: Let the sheep do the sampling. Environ. Manage. 22, 145-152. doi: 10.1007/s002679900091

Zar, J. H. (2010). Biostatistical Analysis, 5th Edn. Upper Saddle River, NJ: Pearson Prentice-Hall.

Conflict of Interest Statement: The authors declare that the research was conducted in the absence of any commercial or financial relationships that could be construed as a potential conflict of interest.

Copyright $\odot 2016$ Codron, Codron, Sponheimer and Clauss. This is an open-access article distributed under the terms of the Creative Commons Attribution License (CC $B Y)$. The use, distribution or reproduction in other forums is permitted, provided the original author(s) or licensor are credited and that the original publication in this journal is cited, in accordance with accepted academic practice. No use, distribution or reproduction is permitted which does not comply with these terms. 